\title{
Repeatedly reactivated memories become more resistant to hippocampal damage
}

\author{
Hugo Lehmann ${ }^{1}$ and Kathryn C. McNamara \\ Psychology Department, Trent University, Peterborough, Ontario, Canada K9J7B8
}

\begin{abstract}
We examined whether repeated reactivations of a context memory would prevent the typical amnesic effects of post-training damage to the hippocampus (HPC). Rats were given a single contextual fear-conditioning session followed by 10 reactivations, involving a brief return to the conditioning context (no shock). Subsequently, the rats received sham or complete lesions of the HPC. When tested for retention, the HPC rats that experienced the reactivations froze significantly more than nonreactivation HPC rats and did not significantly differ from their respective control group. These findings suggest that memory reactivations contribute to long-term memories becoming independent of the HPC.
\end{abstract}

There is general consensus that damage to the hippocampus (HPC) causes retrograde amnesia, a deficit in remembering memories acquired prior to the onset of the damage. In some instances, recently acquired memories seem more likely to be lost following HPC damage than remotely acquired memories (Scoville and Milner 1957; Winocur 1990; Zola-Morgan and Squire 1990). This phenomenon is termed temporally graded retrograde amnesia and is taken as evidence that memories undergo long-term consolidation, meaning that memories change over a protracted time period from being HPC-dependent to being independently represented in other networks (e.g., neocortex) (McClelland et al. 1995; Nadel and Moscovitch 1997; Squire et al. 2004; Frankland and Bontempi 2005; Winocur et al. 2010).

Distributed Reinstatement Theory, however, is an alternative account for how memories may become independent of the HPC (Sutherland et al. 2010). This view suggests that each time an event is reexperienced there is incremental strengthening of the memory in non-HPC systems leading to one that is increasingly more resistant to HPC damage. Thus, the passage of time is not the central feature for how memories become independent of the HPC, though it does offer more opportunity for reinstatements. A recently published study examining the effects of complete HPC damage on contextual fear conditioning in rats strongly supports this view (Lehmann et al. 2009). Contextual fear conditioning typically involves pairing a configuration of static cues, or context, with an aversive event (e.g., foot shock), such that when the rats are returned to the context they show fearrelated behaviors (e.g., freezing) that can be used as indices of memory. Several studies suggest that damage to the HPC can cause temporally graded retrograde amnesia in this task (Kim and Fanselow 1992; Anagnostaras et al. 1996; Maren et al. 1997; Wang et al. 2009; Winocur et al. 2009), though compelling findings also refute the possibility that remote memories for contextual fear conditioning can be spared following HPC damage (Lehmann et al. 2007b; Sutherland et al. 2008). Nevertheless, contextual fear conditioning can survive complete HPC damage if it was acquired over several sessions rather than in a single conditioning session (Lehmann et al. 2009). Therefore, distributed reinstatements or the distribution of the learning experience enables other brain areas to acquire and retain a contextual conditioning representation that does not critically require the HPC.

\section{'Corresponding author.}

E-mail hugolehmann@trentu.ca; fax (705) 748-1580.

Article is online at http://www.learnmem.org/cgi/doi/10.1101//m.2000811.
Memory reactivation, triggering recall or cued retrieval, induces new protein synthesis and causes changes in neuronal plasticity (Nader and Einarsson 2010). Cued-retrieval plasticity has been observed in the HPC (Debiec et al. 2002; Lee et al. 2004) and other regions, such as the amygdala (Nader et al. 2000; Duvarci et al. 2008), perirhinal (Romero-Granados et al. 2010), entorhinal (Kelly et al. 2003), and prefrontal cortices (Romero-Granados et al. 2010). The purpose of cued-retrieval plasticity is unclear, but it has been proposed that it leads to memory updating and transformation (Sara 2000a; Dudai and Eisenberg 2004; Lee 2009; Hardt et al. 2010) including the strengthening of a memory (Sara 2000b; Lee 2008). We thus examined whether cued retrieval may be similar to that of reexperiencing an event as proposed by Distributed Reinstatement Theory. More specifically, we examined whether memory reactivation may be a sufficient reinstatement process for making contextual fear conditioning memories become resistant to extensive HPC damage in rats. Noteworthy, this question contrasts with the majority of the reconsolidation research that has focused on examining how memories become vulnerable in the hours that follow a reactivation.

Adult male rats were given a single contextual fear conditioning session followed by 10 reactivations distributed over $5 \mathrm{~d}$ (Reactivation condition). Specifically, on day 1, rats were placed in a conditioning chamber and received 10 shocks $(0.75 \mathrm{~mA} / 2$ sec) over $15 \mathrm{~min}$. For the following $5 \mathrm{~d}$, the rats were returned to the same context for $15 \mathrm{sec}$ in the morning and again for $15 \mathrm{sec}$ in the afternoon to induce memory reactivation. Importantly, no shock was delivered during these reactivations. One to $3 \mathrm{~d}$ after the last reactivation, the rats either received sham surgery or neurotoxic lesions of the entire HPC (see Lehmann et al. 2007a). Ten to 14-d after surgery, each rat was returned to the conditioning context for a 5-min retention test during which freezing, defined as complete immobility except for breathing, was used as an index of memory. Given that it was predicted that reactivations would mitigate HPC-induced amnesia, another condition was included as a positive control for the typical retrograde amnesic effects of HPC damage on contextual fear conditioning. In this condition, rats received 10 brief preexposures to the context followed by a single contextual fear conditioning session (Preexposure condition). The preexposure procedure was identical to the reactivation procedure (15 sec; twice a day for 5 consecutive days) with the exception that it was given prior to the single 10-shock fearconditioning session. Thus, the amount of time spent in the conditioning context as well as the number of shocks received was 
exactly the same for the rats in the Preexposure and Reactivation condition. The Preexposure rats then received surgery 7 to $9 \mathrm{~d}$ after the single-shock session, an interval that matches that of the Reactivation condition and eliminated long-term consolidation as a possible confound between conditions. The retention test for the rats in the Preexposure condition was identical to those in the Reactivation condition. Figure 1 illustrates the experimental design.

HPC damage caused retrograde amnesia for the rats in the Preexposure, but not Reactivation, condition (Fig. 2). An ANOVA with between-group factors condition (Preexposure and Reactivation) and lesion (Sham and HPC) revealed a significant main effect of lesion $\left(F_{(1,32)}=19.325, P<0.001\right)$, but no significant effect of condition $\left(F_{(1,32)}=0.454, P=0.505\right)$. However, the lesion $\times$ condition interaction was significant $\left(F_{(1,32)}=\right.$ $5.504, P<0.05)$, indicating that the lesion effect differed according to whether the rats were in the Preexposure or Reactivation condition. Least significant difference (LSD) pairwise comparisons revealed that the HPC rats in the Preexposure group froze significantly less than their respective Sham group $(P<0.05)$, suggesting that the HPC damage impaired memory. In contrast, the HPC rats from the Reactivation condition did not freeze significantly less than their respective Sham group $(P=0.158)$ and froze significantly more that the HPC rats in the Preexposure condition $(P<0.05)$, suggesting that HPC damage induced after reactivations failed to impair memory. Also, the repeated reactivations did not cause substantial extinction because no significant difference was found between the two Sham groups $(P=0.232)$.

To be included in the study the lesion rats had to have sustained at least $75 \%$ damage to the HPC (see Lehmann et al. 2010) and no substantial damage outside the targeted region. Figure 3 illustrates and summarizes the histological findings. It
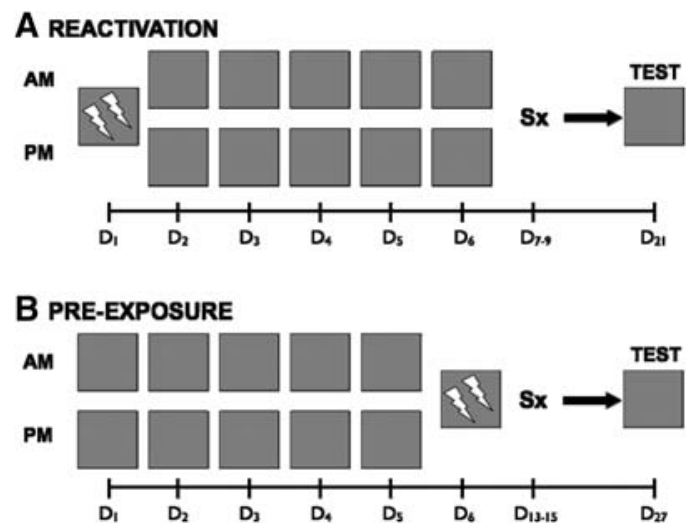

Figure 1. Illustration of the experimental design used in the Reactivation condition $(A)$ and the Preexposure condition $(B)$. In $A$, the rats were initially placed in the conditioning chamber for $15 \mathrm{~min}$ and received the first of 10 foot shocks $(0.75 \mathrm{~mA} / 2 \mathrm{sec})$ at the 300 -sec mark and then one every following $58 \mathrm{sec}$ after shock offset. For the next $5 \mathrm{~d}$, the rats were returned to the context for $15 \mathrm{sec}$ in the morning and then again in the afternoon to induce a total of 10 distributed reactivations. Importantly, no shocks were delivered during these reactivation sessions. One to $3 \mathrm{~d}$ after, the rats received sham or HPC damage $(\mathrm{S} x)$ and approximately $10 \mathrm{~d}$ after the rats were returned to the chamber to assess freezing over a 5-min retention test. In $B$, the rats were placed in the conditioning chamber for $15 \mathrm{sec}$ in the morning and again in the afternoon for 5 consecutive days. On the sixth day, the rats received a 10 -shock conditioning session identical to the one previously described for the rats in the Reactivation condition. The rats received sham or HPC damage 7-9 d later. A 5-min retention test was given approximately 10 d later. Noteworthy, the number of shocks, context exposure time, and interval between the actual context-shock pairing session and surgery were matched between both conditions.



Figure 2. Mean (+SEM) percent time freezing by Sham and HPC rats during the retention test. The Preexposure-HPC rats showed significantly less freezing $\left({ }^{*} P<0.001\right)$ than the Preexposure-Sham rats, suggesting that the lesions caused profound retrograde amnesia for contextual fear conditioning learned in a single session 7-10 d before surgery. The Reactivation-HPC rats, however, did not suffer from retrograde amnesia because they did not freeze significantly less than the Reactivation-Sham rats $(P=0.158)$. Moreover, the HPC rats from the Reactivation condition froze significantly more than the HPC rats from the Preexposure condition $(\# P<0.05)$. Thus, distributed reactivations mitigated the retrograde amnesic effects of HPC damage in contextual fear conditioning and enabled the strengthening of HPC independent memory.

is estimated that an average of $84.1 \%$ of the HPC was damaged in the Reactivation condition, $88.7 \%$ in the Preexposure condition, and no significant difference was found between both groups $\left(t_{(15)}=1.562, P=0.139\right)$. Clearly, the amount of HPC damage for both lesion groups was extensive and exceeded, or was comparable, to that of other studies investigating the effects of HPC damage on memory (Kim and Fanselow 1992; Maren et al. 1997; Anagnostaras et al. 1999; Lehmann et al. 2007b; Sutherland et al. 2008). Therefore, it is highly unlikely that the better retention test performance of the HPC-Reactivation vs. the HPC-Preexposure group can be accounted for by differences in extent of HPC damage.

The current findings demonstrate that repeated cued retrievals of a HPC-dependent memory causes strengthening of a representation in other brain areas that ultimately can be expressed without necessary contribution of the HPC. The retrograde amnesia following HPC damage in the Preexposure rats confirms that contextual fear conditioning acquired in a single session normally depends on the HPC (Kim and Fanselow 1992; Maren et al. 1997; Anagnostaras et al. 1999; Lehmann et al. 2007b; Sutherland et al. 2008; Winocur et al. 2009). Yet, the HPC rats from the Reactivation condition did not show deficits compared with their respective control group and showed significantly better retention than the HPC rats from the Preexposure condition. This spared memory following distributed reactivations implies that a non-HPC system supported expression during the retention test. One could argue, however, that the undamaged HPC tissue $(\sim 15 \%)$ in the Reactivation condition actually supported the memory because the reactivations created a stronger and/or more distributed representation in the HPC. This would be consistent with a tenet of the Multiple Trace Theory that argues that some memories are more resistant to HPC damage because they have developed more traces across the HPC. However, no significant correlation $\left(\mathrm{r}_{(8)}=0.294, P=0.474\right)$ was found between the amount of remaining tissue and retention performance in the Reactivation condition, suggesting that any remaining tissue in the HPC unlikely accounted for the spared memory. Moreover, 
A

Aeactivation
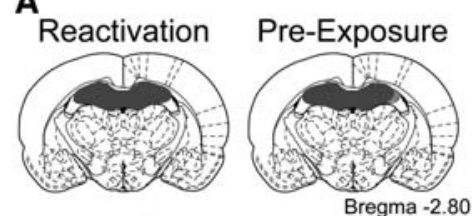

Bregma $-2.80 \mathrm{~mm}$
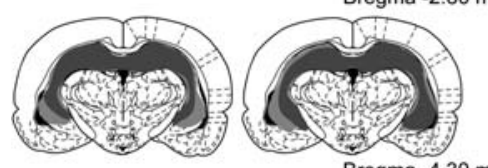

Bregma $-4.30 \mathrm{~mm}$

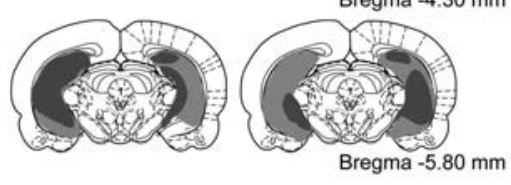

C

Estimates of the percent HPC damage.

\begin{tabular}{lccccc}
\hline Group & $\mathbf{n}$ & Smallest & Largest & Average & $\begin{array}{c}\text { Standard } \\
\text { Deviation }\end{array}$ \\
\hline \multirow{2}{*}{ Reactivation } & 8 & 76.8 & 93.8 & 84.1 & 2.16 \\
& & & & & \\
Pre-Exposure & 9 & 79 & 96.9 & 88.7 & 1.98 \\
\hline
\end{tabular}

Figure 3. Histological summary and illustration of the amount HPC damage for the lesion rats included in the study. $(A)$ Representation of the smallest (dark gray) and largest (light gray) lesion observed bilaterally through the rostral and caudal extent of the HPC for HPC-Reactivation and HPC-Preexposure rats. Atlas plates are from Paxinos and Watson (1997). (B) Photomicrographs of a representative lesion in which $86 \%$ of the cell fields were damaged in the HPC. (C) Stereological quantification of the amount of HPC damage for the rats in the two lesion groups.

the lesions in the current study are as large, and often larger, than those found in other studies that also claim that memories can become independent of the HPC (for example, see Kim et al. 1992; Maren et al. 1997; Anagnostaras et al. 1999; Ross and Eichenbaum 2006; Tse et al. 2007; Quinn et al. 2008; Wang et al. 2009; Winocur et al. 2009; Broadbent et al. 2010).

The majority of memory reactivation studies have examined reconsolidation processes and how memories become subject to modification in the minutes or hours that follow a reactivation. For instance, extensive evidence suggests that pharmacological manipulations, such as giving protein synthesis inhibitors and adrenergic antagonists, can cause amnesia when given soon after a reactivation (Przybyslawski et al. 1999; Nader et al. 2000; Debiec et al. 2002; Duvarci et al. 2008; Milton et al. 2008; Robinson and Franklin 2010). Likewise, memory can be pharmacologically enhanced immediately following a reactivation (Tronson et al. 2006). It has also been shown that additional learning trials may strengthen a memory by enabling cellular reconsolidation processes that are dissociable from the consolidation of new information (Lee 2008). These findings have led to the view that memories become labile following reactivation and undergo updating and transformation, including the addition of new information, strengthening, or the distortion of the original memory (Sara 2000a; Dudai and Eisenberg 2004; Lee 2009; Hardt et al. 2010). The current findings, however, offer a slightly different perspective on the role of reconsolidation in memory transformation and strengthening. Here we show that reactivation, uncomplicated by the presentation of the reward or unconditioned stimulus (i.e., shock), enables the strengthening and/or expansion of the neural network supporting the original memory. Thus, this is an instance in which memory was strengthened solely through triggering retrieval. Moreover, a key and novel feature of this study is that the cued retrieval and its ensuing reconsolidation processes made a memory become independent (i.e., not critically required) of a neural system it initially required on and ultimately less vulnerable to insult.

Mechanistically, reactivation-induced protein synthesis most likely accounted for the strengthening of the memory in non-HPC systems. New protein synthesis occurs in several brain regions following memory reactivation (Nader et al. 2000; Debiec et al. 2002; Kelly et al. 2003; Duvarci et al. 2008; Romero-Granados et al. 2010). In contextual fear conditioning, reactivation-induced protein synthesis has been demonstrated in the HPC (Lee et al. 2004) and amygdala (Duvarci et al. 2008). Given that a nonHPC system supported the memory, then the amygdala is the most likely structure to have benefited from the repeated reactivations. Nonetheless, regions such as the rhinal and cingulate cortices that are known to play major roles in supporting contextual fear memories (Bucci et al. 2000; Frankland et al. 2004) may have also undergone reactivation-induced plasticity and contributed to the support of the HPC-independent memory.

Sutherland et al. (2010) recently theorized that distributed reinstatements could rapidly strengthen a normally HPC-dependent memory in non-HPC systems. The theory argues that for some memories the HPC interferes with or overshadows the formation of an independent representation in non-HPC systems. In this instance, successful retention performance requires the HPC. However, the theory also proposes that each reinstatement of an event may cause incremental strengthening of a non-HPC representation and that after a sufficient number of reinstatements the non-HPC system may support retention and recall without necessary contribution from the HPC. The latter has been similarly proposed by Rudy and O'Reilly (2001), and recent evidence clearly supports the view that a memory acquired over distributed rather than massed learning is more likely to become independent of the HPC. For instance, contextual fear conditioning acquired over 11 conditioning sessions is not affected by post-training HPC damage, whereas fear conditioning acquired in a single massed session is severely impaired (Lehmann et al. 2009). Similarly, object recognition memory, which is typically dependent on the HPC, becomes less vulnerable to HPC damage by increasing the number of learning sessions from 5 to 30 (Sutherland et al. 2010). Thus, additional learning sessions may enable non-HPC systems to establish a representation that can independently support performance on a retention test. An interesting feature of the current study for Distributed Reinstatement Theory is that the reinstatements did not require that all features of the original learning episode be present. Simply triggering retrieval by returning the rats to the conditioning context was sufficient to strengthen a representation in non-HPC systems.

Since Scoville and Milner (1957) described temporally graded retrograde amnesia following a medial temporal lobectomy in well-known patient H.M., the HPC has generally been viewed as a temporary contributor to long-term memories until they become consolidated in neocortical areas (McClelland et al. 1995; Nadel and Moscovitch 1997; Squire et al. 2004; Frankland and Bontempi 2005; Winocur et al. 2010). Although temporally graded retrograde amnesia following HPC damage has been reported across species and in a variety of tasks (see Squire et al. 2004; Winocur et al. 2010), the phenomenon is still questioned because a large body of evidence also demonstrates that the simple passage of time is insufficient for memories to become HPC independent (see Sutherland et al. 2010). The current findings do not disconfirm that reorganization of memories may occur over a protracted time period, but they suggest that it is not a 
necessary feature. Specifically, the present findings show that reactivations distributed over a period too short for systems consolidation can increase/strengthen the neural network supporting a memory and make it less vulnerable to HPC insult.

In conclusion, the neural network supporting a contextual fear conditioning memory was strengthened by distributed reactivations, to the point that a normally HPC-dependent memory no longer required the HPC for successful expression. That reactivations can cause a memory to rely on additional neural systems offers a new perspective on how cued-retrieval plasticity may transform and update memories. Moreover, that distributed reactivations rapidly strengthened a contextual fear conditioning representation outside the HPC supports Distributed Reinstatement Theory, which argues that repeated externally triggered reinstatements is a key feature for memories shifting from being HPC dependent to independent.

\section{Acknowledgments}

We thank Fraser T. Sparks and Dr. Liana Brown for comments on an earlier version of this manuscript. We also thank Meagan Low and Chris Wright for technical assistance with behavioral testing and histology. Grant Sponsor: NSERC

\section{References}

Anagnostaras SG, Maren S, Fanselow MS. 1996. Time-limited retrograde amnesia of contextual fear conditioning after electrolytic dorsal hippocampal lesions in rats. In Annual Meeting for the Society of Neuroscience. Washington, DC.

Anagnostaras SG, Maren S, Fanselow MS. 1999. Temporally graded retrograde amnesia of contextual fear after hippocampal damage in rats: Within-subjects examination. J Neurosci 19: 1106-1114.

Broadbent NJ, Gaskin S, Squire LR, Clark RE. 2010. Object recognition memory and the rodent hippocampus. Learn Mem 17: 794-800.

Bucci DJ, Phillips RG, Burwell RD. 2000. Contributions of postrhinal and perirhinal cortex to contextual information processing. Behav Neurosci 114: $882-894$.

Debiec J, LeDoux JE, Nader K. 2002. Cellular and systems reconsolidation in the hippocampus. Neuron 36: 527-538.

Dudai Y, Eisenberg M. 2004. Rites of passage of the engram: Reconsolidation and the lingering consolidation hypothesis. Neuron 44: $93-100$.

Duvarci S, Nader K, LeDoux JE. 2008. De novo mRNA synthesis is required for both consolidation and reconsolidation of fear memories in the amygdala. Learn Mem 15: 747-755.

Frankland PW, Bontempi B. 2005. The organization of recent and remote memories. Nat Rev Neurosci 6: 119-130.

Frankland PW, Bontempi B, Talton LE, Kaczmarek L, Silva AJ. 2004. The involvement of the anterior cingulate cortex in remote contextual fear memory. Science 304: $881-883$.

Hardt O, Einarsson EO, Nader K. 2010. A bridge over troubled water: Reconsolidation as a link between cognitive and neuroscientific memory research traditions. Annu Rev Psychol 61: 141-167.

Kelly A, Laroche S, Davis S. 2003. Activation of mitogen-activated protein kinase/extracellular signal-regulated kinase in hippocampal circuitry is required for consolidation and reconsolidation of recognition memory. J Neurosci 23: 5354-5360.

Kim JJ, Fanselow MS. 1992. Modality-specific retrograde amnesia of fear. Science 256: $675-677$

Kim JJ, Fanselow MS, DeCola JP, Landeira-Fernandez J. 1992. Selective impairment of long-term but not short-term conditional fear by the N-methyl-D-aspartate antagonist APV. Behav Neurosci 106: 591-596.

Lee JL. 2008. Memory reconsolidation mediates the strengthening of memories by additional learning. Nat Neurosci 11: 1264-1266.

Lee JL. 2009. Reconsolidation: Maintaining memory relevance. Trends Neurosci 32: 413-420.

Lee JL, Everitt BJ, Thomas KL. 2004. Independent cellular processes for hippocampal memory consolidation and reconsolidation. Science 304: 839-843.

Lehmann H, Clark BJ, Whishaw IQ. 2007a. Similar development of cued and learned home bases in control and hippocampal-damaged rats in an open field exploratory task. Hippocampus 17: 370-380.

Lehmann H, Lacanilao S, Sutherland RJ. 2007b. Complete or partial hippocampal damage produces equivalent retrograde amnesia for remote contextual fear memories. Eur J Neurosci 25: 1278-1286.
Lehmann H, Sparks FT, Spanswick SC, Hadikin C, McDonald RJ, Sutherland RJ. 2009. Making context memories independent of the hippocampus. Learn Mem 16: 417-420.

Lehmann H, Sparks FT, O'Brien J, McDonald RJ, Sutherland RJ. 2010. Retrograde amnesia for fear-potentiated startle in rats after complete, but not partial, hippocampal damage. Neuroscience 167: 974-984.

Maren S, Aharonov G, Fanselow MS. 1997. Neurotoxic lesions of the dorsal hippocampus and Pavlovian fear conditioning in rats. Behav Brain Res 88: $261-274$.

McClelland JL, McNaughton BL, O’Reilly RC. 1995. Why there are complementary learning systems in the hippocampus and neocortex: Insights from the successes and failures of connectionist models of learning and memory. Psychol Rev 102: 419-457.

Milton AL, Lee JL, Everitt BJ. 2008. Reconsolidation of appetitive memories for both natural and drug reinforcement is dependent on \{beta\}-adrenergic receptors. Learn Mem 15: 88-92.

Nadel L, Moscovitch M. 1997. Memory consolidation, retrograde amnesia and the hippocampal complex. Curr Opin Neurobiol 7: 217-227.

Nader K, Einarsson EO. 2010. Memory reconsolidation: An update. Ann N Y Acad Sci 1191: 27-41.

Nader K, Schafe GE, Le Doux JE. 2000. Fear memories require protein synthesis in the amygdala for reconsolidation after retrieval. Nature 406: $722-726$.

Paxinos G, Watson C. 1997. The rat brain in stereotaxic coordinates. Academic Press, San Diego, CA.

Przybyslawski J, Roullet P, Sara SJ. 1999. Attenuation of emotional and nonemotional memories after their reactivation: Role of beta adrenergic receptors. J Neurosci 19: 6623-6628.

Quinn JJ, Ma QD, Tinsley MR, Koch C, Fanselow MS. 2008. Inverse temporal contributions of the dorsal hippocampus and medial prefrontal cortex to the expression of long-term fear memories. Learn Mem 15: 368-372.

Robinson MJ, Franklin KB. 2010. Reconsolidation of a morphine place preference: Impact of the strength and age of memory on disruption by propranolol and midazolam. Behav Brain Res 213: 201-207.

Romero-Granados R, Fontan-Lozano A, Delgado-Garcia JM, Carrion AM. 2010. From learning to forgetting: Behavioral, circuitry, and molecular properties define the different functional states of the recognition memory trace. Hippocampus 20: 584-595.

Ross RS, Eichenbaum H. 2006. Dynamics of hippocampal and cortical activation during consolidation of a nonspatial memory. J Neurosci 26: $4852-4859$.

Rudy JW, O'Reilly RC. 2001. Conjunctive representations, the hippocampus, and contextual fear conditioning. Cogn Affect Behav Neurosci 1: 66-82.

Sara SJ. 2000a. Retrieval and reconsolidation: Toward a neurobiology of remembering. Learn Mem 7: 73-84.

Sara SJ. 2000b. Strengthening the shaky trace through retrieval. Nat Rev Neurosci 1: 212-213.

Scoville WB, Milner B. 1957. Loss of recent memory after bilateral hippocampal lesions. J Neurochem 20: 11-21.

Squire LR, Stark CE, Clark RE. 2004. The medial temporal lobe. Annu Rev Neurosci 27: 279-306.

Sutherland RJ, O'Brien J, Lehmann H. 2008. Absence of systems consolidation of fear memories after dorsal, ventral, or complete hippocampal damage. Hippocampus 18: 710-718.

Sutherland RJ, Sparks FT, Lehmann H. 2010. Hippocampus and retrograde amnesia in the rat model: A modest proposal for the situation of systems consolidation. Neuropsychologia 48: 2357-2369.

Tronson NC, Wiseman SL, Olausson P, Taylor JR. 2006. Bidirectional behavioral plasticity of memory reconsolidation depends on amygdalar protein kinase A. Nat Neurosci 9: 167-169.

Tse D, Langston RF, Kakeyama M, Bethus I, Spooner PA, Wood ER, Witter MP, Morris RG. 2007. Schemas and memory consolidation. Science 316: 76-82.

Wang SH, Teixeira CM, Wheeler AL, Frankland PW. 2009. The precision of remote context memories does not require the hippocampus. Nat Neurosci 12: 253-255.

Winocur G. 1990. Anterograde and retrograde amnesia in rats with dorsal hippocampal or dorsomedial thalamic lesions. Behav Brain Res 38: $145-154$.

Winocur G, Frankland PW, Sekeres M, Fogel S, Moscovitch M. 2009. Changes in context-specificity during memory reconsolidation: Selective effects of hippocampal lesions. Learn Mem 16: 722-729.

Winocur G, Moscovitch M, Bontempi B. 2010. Memory formation and long-term retention in humans and animals: Convergence towards a transformation account of hippocampal-neocortical interactions. Neuropsychologia 48: 2339-2356.

Zola-Morgan SM, Squire LR. 1990. The primate hippocampal formation: Evidence for a time-limited role in memory storage. Science 250: 288-290.

Received September 2, 2010; accepted in revised form November 23, 2010. 


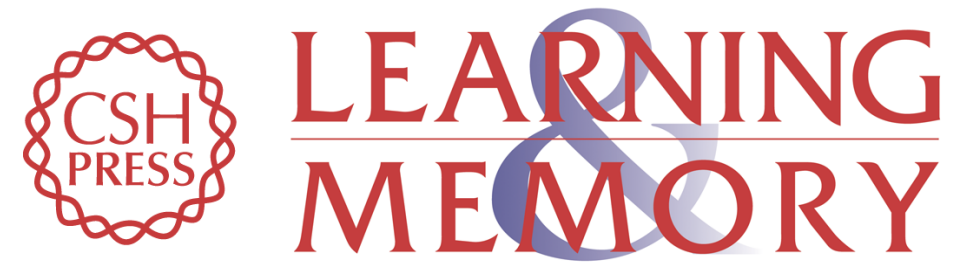

\section{Repeatedly reactivated memories become more resistant to hippocampal damage}

Hugo Lehmann and Kathryn C. McNamara

Learn. Mem. 2011, 18:

Access the most recent version at doi:10.1101/lm.2000811

References This article cites 44 articles, 15 of which can be accessed free at: http://learnmem.cshlp.org/content/18/3/132.full.html\#ref-list-1

License

Email Alerting Receive free email alerts when new articles cite this article - sign up in the box at the Service top right corner of the article or click here. 